\title{
Epidural analgesia for painless labour and its impact on neonatal outcome
}

\author{
Amrita Chaurasia, Nidhi Sachan, Neelam Singh \\ Corresponding author: Dr. Nidhi Sachan, Assistant Prof , Dept of OBGY, MLNMC, Prayagraj, India; \\ Email : sachannidhi05@gmail.com
}

Distributed under Attribution-Non Commercial - Share Alike 4.0 International (CC BY-NC-SA 4.0)

\begin{abstract}
Objectives: To evaluate the effectiveness of epidural labour and its impact on maternal and neonatal outcome. Methods: Epidural analgesia was given to 50 patients and 50 were chosen as control with no analgesia. All the patients in the study were primi, with vertex presentation, with no contraindication for vaginal delivery. Duration of labour, mode of delivery, assisted vaginal delivery, pain scores, fetal heart rate and Apgar score of neonates were assessed. Results: There was no statistical significance in the rate of caesarian section in both the groups $(p=0.69)$. Duration of second stage of labour was prolonged in study group, and the difference was statistically significant ( $\mathrm{p}<$ 0.001). There was no difference in baseline fetal heart rate (FHR) in both the groups. There was a significant reduction in Vas (Visual analogue scale) score of the parturient in study group, with mean Vas score reaching $<1$ in 30 minutes. There was no statistical difference in Apgar score of both the groups. Conclusion: Epidural analgesia is an effective way of painless labour, with no significant maternal and neonatal side effects.
\end{abstract}

Keywords: Epidural, Vas score, labour.

Labour pain is one of the most severe pains which have been ever evaluated and its fear is one of the reasons women would not go for natural delivery. ACOG says "There is no other circumstance in which it is considered acceptable for an individual to experience untreated severe pain that is amenable to safe intervention while the individual is under a physician's care." Search for effective methods of pain relief during labour have been a field of research.

Since ages scientific advancements have been made to alleviate labour pains, which is the most fearful pain of women's life that she has to bear inevitably. Traditionally opioids like pethidine have been used to curtail this pain, but this had very high chances of fetal depression ${ }^{1}$. In succession came tramadol, but was not very effective with higher pain scores. Epidural analgesia has been established by various trials as an effective means of pain relief. But its impact on labour and neonatal outcome has been a matter of concern. Present study was done to evaluate the impact of epidural analgesia on labour and neonatal outcome.

\section{Materials and methods}

This prospective observational study was carried out in the department of Obstetrics and Gynaecology, MLNMC, Prayagraj for a period of one year $\left(1^{\text {st }}\right.$ February 2019 to $1^{\text {st }}$ February 2020). After approval from institutional ethical committee, this study was conducted at Swarooprani Nehru Hospital. 100 numbers of term primigravida parturients, who gave consent and had single live fetus, with vertex presentation and without any contraindication for vaginal delivery, were included in the study. Parturients who requested epidural analgesia for pain relief, were kept in

Received: $11^{\text {th }}$ June 2020. Peer review completed: $10^{\text {th }}$ July 2020, Accepted: $12^{\text {th }}$ July 2020.

Chaurasia A, Sachan N, Singh N. Epidural analgesia for painless labour and its impact on neonatal outcome. The New Indian Journal of OBGYN. 2021; 7(2): 186-89. 
group 1 (Study group). whereas women who wanted to have natural labour without any intervention were kept in group 2 and served as control group. $15 \mathrm{ml}$ of $0.125 \%$ ropivacaine was used as initial dose. Same dose regimen was used as subsequent top up dose on patient's demand for pain relief.

Pain experienced by the parturient was measured using Vas scale which contained pictures of faces depicting pain on one end and smiling face on the other end. In between the two, there were pictures expressing intermediate emotions. The other side had a scale marked from 0 to 100 . The scale had a slider which the patients move to point below the image which they felt expressed their perceived pain.VAS score at the time of epidural insertion was taken as $0 \mathrm{~min}$. It was then assessed every 15 min till 1 hour and then 1 hourly till delivery of baby till delivery of baby.

Epidural was given during cervical dilatation of $4 \mathrm{~cm}$. Time from epidural to delivery was noted and duration of $1^{\text {st }}, 2^{\text {nd }}$ and $3^{\text {rd }}$ stage of labour were compared. Mode of delivery in either group was noted (caesarian/vaginal). Indications for caesarian section were also noted. Late decelerations in cardiotocograph (CTG), or persistent FHR $<110$ OR $>160$ was taken as fatal distress. If head was Total below +2 station, assisted vaginal delivery was tried. Caesarian was done in cases above +2 station or in case of failure of assisted vaginal delivery. Neonatal outcome in both the groups was noted using $1 \mathrm{~min}$ and 5 min Apgar score.

Data was analysed using SPSS 11.5. Descriptive analyses for non parametric variables were expressed in proportion and parametric variables in mean and standard deviation. The treatment difference was assessed using $\mathrm{t}$ test for independent samples for parametric variables and by chi square test for non parametric variables. Statistical significance was assessed using $\mathrm{p}$ value $<0.05$ as significant and $\mathrm{p}=0.0001$ as highly significant.

\section{Results}

Total of 100 term antenatal patients in labour were included in the study. Patients were randomly categorised in two groups. 50 patients who demanded epidural analgesia were kept in group 1 and those who did not want any intervention were kept in group 2. The study group did not have any statistically significant difference with respect to age and BMI (table 1). The p value calculated was $<0.05 .4$ patients in group 1 and 3 patients in group 2 landed in caesarian section. Though there was no difference in the rate of caesarian section in either group ( $p$ value o.69.). The indications of caesarian for prolonged labour were seen in 2 cases in group 1, while in group 2 all the three cases were done for fetal distress (table 2).

\begin{tabular}{lllll} 
Table 1: Age and BMI distribution & & \\
\hline Parameters & & $\begin{array}{l}\text { Group 1 } \\
\text { (with epidural) } \\
\text { n=50 } \\
\text { Number (\%) }\end{array}$ & $\begin{array}{l}\text { Group 2 } \\
\text { (without } \\
\text { epidural) } \\
\text { Number (\%) }\end{array}$ & $\begin{array}{l}\text { P } \\
\text { value }\end{array}$ \\
& & $17(34 \%)$ & $13(26 \%)$ & 0.38 \\
\hline Age & $<25$ & $29(58 \%)$ & $32(64 \%)$ & 0.53 \\
distribution & $25-35$ & $4(8 \%)$ & $5(10 \%)$ & 0.52 \\
in years & $36-40$ & $\mathbf{5 0}(\mathbf{1 0 0} \%)$ & $\mathbf{5 0}(\mathbf{1 0 0} \%)$ & \\
Total & & $4(11 \%)$ & $1(6 \%)$ & 0.16 \\
\hline BMI & $<18.5$ & $40(80 \%)$ & $45(88 \%)$ & 0.11 \\
distribution & $18.5-24.9$ & $6(9 \%)$ & $4(6 \%)$ & 0.5 \\
in Kg/m & $\geq 25$ & $\mathbf{5 0}(\mathbf{1 0 0} \%)$ & $\mathbf{5 0}(\mathbf{1 0 0} \%)$ & \\
Total & &
\end{tabular}

Mean time from epidural to delivery was comparable in both the groups $(p=0.19)$ (table 3$)$, but when individual stages of labour were studied by applying student $t$ test,
Table 2: Mode of delivery

ery

\begin{tabular}{|c|c|c|c|c|}
\hline \multicolumn{2}{|l|}{ Mode of delivery } & $\begin{array}{l}\text { Group1 } \\
\text { (with epidural) } \\
\text { Number }(\%)\end{array}$ & $\begin{array}{l}\text { Group } 2 \\
\text { (without epidural) } \\
\text { Number (\%) }\end{array}$ & $P$ value \\
\hline \multicolumn{2}{|l|}{ Vaginal } & $40(80 \%)$ & $44(88 \%)$ & 0.27 \\
\hline \multicolumn{2}{|c|}{ Assisted vaginal delivery } & $6(12 \%)$ & $3(6 \%)$ & 0.32 \\
\hline \multicolumn{2}{|l|}{ Caesarian section } & $4(8 \%)$ & $3(6 \%)$ & 0.69 \\
\hline \multirow[t]{2}{*}{ Caesarian section } & Fetal distress & $2(4 \%)$ & $3(6 \%)$ & \\
\hline & Prolonged $2^{\text {nd }}$ stage & $2(4 \%)$ & 0 & \\
\hline Total & & $50(100 \%)$ & $50(100 \%)$ & \\
\hline
\end{tabular}

second stage of labour was significantly prolonged in group 1 with $\mathrm{p}$ value of 0.001 (table 4). No statistical difference in duration of $1^{\text {st }}$ and $3^{\text {rd }}$ stages of labour was observed. Although second stage was significantly prolonged in group 1 , but mean FHR in both the groups remained comparable with time throughout labour (table 5).

\begin{tabular}{lllll}
\multicolumn{2}{l}{ Table 3: Time from epidural to delivery } \\
\hline Groups & $\begin{array}{l}\text { No of } \\
\text { cases }\end{array}$ & $\begin{array}{l}\text { Mean time from } \\
\text { epidural to } \\
\text { delivery in min }\end{array}$ & SD & $\begin{array}{l}\text { Student t } \\
\text { test } \\
\text { P value }\end{array}$ \\
\hline $\begin{array}{l}\text { Group 1 (with } \\
\text { epidural) }\end{array}$ & 46 & 352.83 & 13.10 & $\begin{array}{l}\text { P value - } \\
0.19\end{array}$ \\
\hline $\begin{array}{l}\text { Group 2 (without } \\
\text { epidural) }\end{array}$ & 47 & 349.32 & 13.07 & \\
\hline
\end{tabular}

Additionally, maximum number of babies had APGAR of $>7$ at $1 \mathrm{~min}$ and $5 \mathrm{~min}$ in both the groups. There was no statistical difference in APGAR score in both the groups ( $p$ value 0.46 and 0.55 ) at $1 \mathrm{~min}$ and $5 \mathrm{~min}$ respectively (table 6).

Most significant observation of our study was seen in Vas score (table 7, figure 1). There was no statistical difference in the Vas score of both the groups at the time of epidural insertion. However after that, mean Vas score of group 1 was significantly lower as compared to group 2 when assessed at $0,5,15,30,60,120,180,240,300$ and 360 minutes. In group 1 , the mean Vas score started to decrease 
The New Indian Journal of OBGYN. 2021 (January-June);7(2)

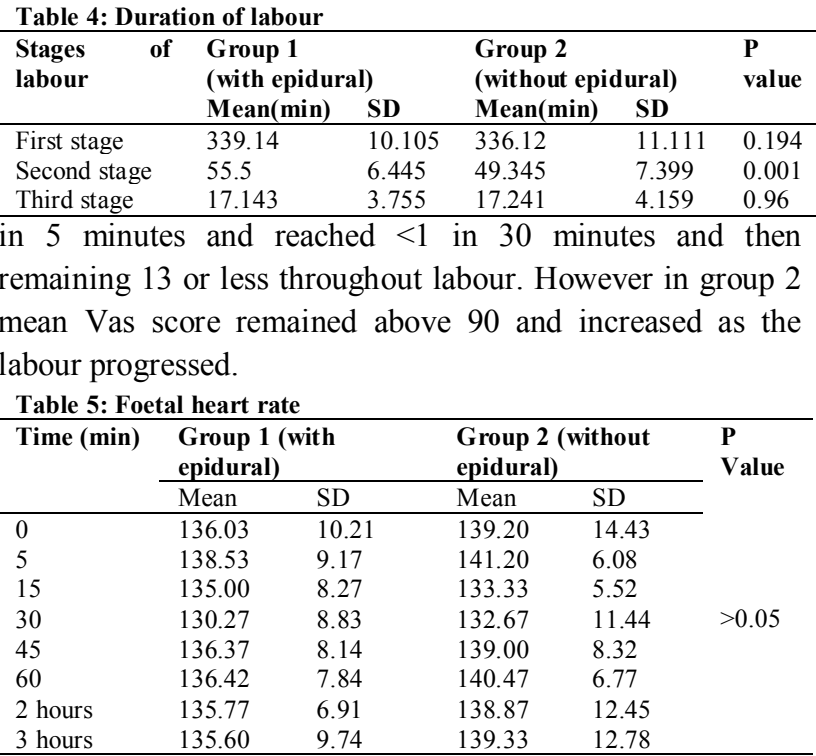

\begin{tabular}{lllll}
\multicolumn{2}{l}{ Table 6: Apgar score of the neonate } \\
\hline Parameters & & $\begin{array}{l}\text { Group 1 } \\
\text { Number (\%) }\end{array}$ & $\begin{array}{l}\text { Group 2 } \\
\text { Number (\%) }\end{array}$ & P value \\
\hline 1 min & $<7$ & $4(8 \%)$ & $6(12 \%)$ & 0.46 \\
Apgar score & $\geq 7$ & $46(92 \%)$ & $42(84 \%)$ & \\
\hline 5 min & $<7$ & $1(2 \%)$ & $2(4 \%)$ & 0.55 \\
Apgar score & $\geq 7$ & $49(98 \%)$ & $48(96 \%)$ & \\
\hline
\end{tabular}

\begin{tabular}{llllll} 
Table 7: Vas score of the mother \\
$\begin{array}{lllll}\text { Time } \\
\text { (min) }\end{array}$ & $\begin{array}{l}\text { Group 1 (with } \\
\text { epidural) }\end{array}$ & $\begin{array}{l}\text { Group 2 (without } \\
\text { epidural) }\end{array}$ & $\begin{array}{l}\text { Student } \\
\text { t test } \\
\text { P value }\end{array}$ \\
\cline { 2 - 5 } & Mean & SD & Mean & SD & 0.33 \\
\hline 0 & 94.33 & 6.7 & 93.23 & 4.5 & 0.0001 \\
5 & 58.000 & 11.56 & 93.87 & 6.1 & 0.0001 \\
15 & 11.000 & 8.449 & 93.93 & 5.3 & 0.0001 \\
30 & 0.333 & 1.269 & 94.12 & 1.2 & 0.0001 \\
45 & 10.833 & 6.706 & 94.23 & 3.5 & 0.0001 \\
60 & 13.033 & 10.347 & 94.24 & 4.6 & 0.0001 \\
120 & 11.000 & 9.595 & 95.5 & 5.3 & 0.0001 \\
180 & 8.500 & 4.577 & 95.4 & 3.7 & 0.0001 \\
240 & 10.234 & 6.023 & 96.37 & 5.2 & 0.0001 \\
300 & 9.32 & 4.84 & 96.89 & 4.9 & 0.0001 \\
\hline
\end{tabular}

\section{Discussion}

Our study showed no increase in rate of caesarian section in epidural group. Similar findings were concluded in comparative study done by Wesam et $\mathrm{al}^{2}$ and Dipti Agarwal et $\mathrm{al}^{3}$. Although, incidence of caesarian was shown to be significantly higher in epidural group in studies done by Chin Chun Liang et al ${ }^{4}$ and EZ Zimmer et $\mathrm{al}^{5}$. This increased rate of caesarian section could be because of various reasons like, type and dose of drug used, presence of other obstetrical factors and lastly the obstetrician's patience.

Rate of instrumental delivery in our study was comparable in both the groups with no statistical difference.

Somuah AM et al did a chocrane study in 2018 and found that rate of instrumental delivery was higher in epidural group (RR 1.44, 95\% CI 1.29 to 1.6; 9948 women; studies $=30$; low quality evidence). But post hoc subgroup analysis of trials conducted after 2005 showed that this effect is negated when trials before 2005 are excluded from this analysis (RR $1.19,95 \%$ CI 0.97 to 1.46). This is because low concentration of newer anaesthetics are being used now with new techniques like patient controlled analgesia. ${ }^{6}$ Previously lidocaine was used as anaesthetic in epidural analgesia, which had significant motor blocking properties. But with ropivacaine, this side effect is less, so is the rate of instrumental delivery.

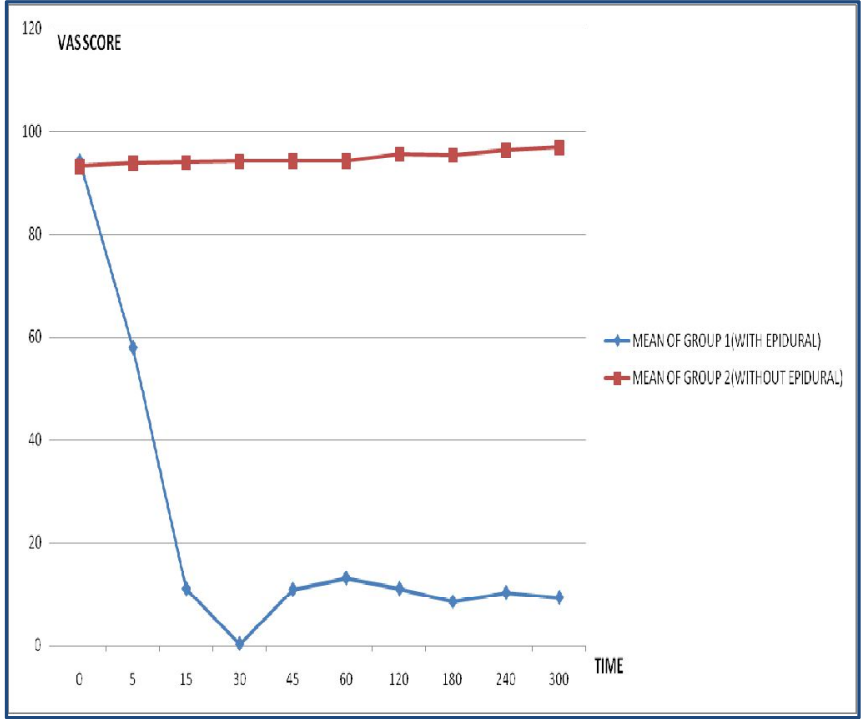

Figure 1: Graphical presentation of the Vas score

A Time from epidural to delivery was comparable in both the groups. But duration of second stage of labour was significantly prolonged in epidural group. In 2018, AnimSomuah $\mathrm{M}$ et al ${ }^{6}$ did a cochrane review including 38 studies and concluded that epidural does prolong second stage of labour. Cause for this prolongation was searched by Fairlie $\mathrm{F}$ et $\mathrm{al}^{7}$, who concluded in their study that epidural analgesia did not appear to influence uterine activity in the first stage but was associated with a lower mean arterial pressure (MAP), contraction frequency and intensity in the second stage. Whatever be the cause, increased duration of second stage was not associated with neonatal morbidity and mortality. Some authors are of different opinion; Angeliki Antonakou ${ }^{8}$ found in their study that epidural analgesia prolongs labour stages 1 and 2 both. Whereas Dipti Agarwal 
The New Indian Journal of OBGYN. 2021 (January-June);7(2)

et $\mathrm{al}^{3}$ reported the duration of first stage of labour to be less and duration of second stage of labour to me more in the epidural group.

The most favourable response was pain relief as assessed by Vas score. As we compared epidural analgesia with no analgesia, obviously the Vas score was significantly less in all stages in epidural group. Many authors like Leighton BL et $\mathrm{al}^{9}$, and Dipty et al ${ }^{3}$ have compared epidural analgesia with systemic opioids and have established. Epidural analgesia to be better than parenteral opioids in pain relief. The rate of achieving analgesia was also quick, with reduction in Vas score to $<1$ in $30 \mathrm{~min}$.

Impact of epidural analgesia on fetus and the neonate was the major concern. In our study, there was slight decrease in variability of FHR tracing in epidural group, but it was not found in all patients, and was not consistent with no statistical difference. Hamza $J$ et al ${ }^{10}$ in their study found that there was decrease in FHR variability in epidural group using lidocaine. However they did not found such effect using bupivacaine. Also in study done by Giorgio Capogna ${ }^{11}$ concluded that epidural analgesia in the absence of maternal hypotension or uterine hypertonus causes minimal changes in FHR.

Apgar score of the neonates in our study was not statistically different in both the groups. This in line with the cochrane review $2018^{6}$ who demonstrated no difference in neonatal Apgar score of 5 mins. Study done by Angeliki Antonakau ${ }^{8}$ demonstrated that Apgar score of neonates at 1 min were significantly lower in the epidural group, but Apgar at 5 mins were not statistically different.

\section{Conclusion}

Epidural Analgesia is an effective tool for painless labour, with no significant maternal and fetal side effects. This could encourage more women to opt for vaginal delivery and hence avoid surgical complications Women in developed countries have good access to this technique, but on the contrary, in developing countries, it is still not widely available. The message is to make "painless labour' an easily accessible option for all women.

\section{Conflict of interest: None. Disclaimer: Nil.}

\section{References}

1. Sosa CG, Balaguer E, Alonso JG, Panizza R, Laborde A, Berrondo C. Meperidine for dystocia during the first of labor: A randomized controlled trial. Am J Obstet Gynaecol. 2004;191:1212-8.

2. Mousa WF, Al-Metwalli R, Mostafa M. Epidural analgesia during labor vs no analgesia: A comparative study. Saudi journal of anaesthesia. 2012; 6(1):36-40.

3. Agarwal D, Makhija B, Arora M, Haritwal A, Gurha P. The Effect of Epidural Analgesia on Labour, Mode of Delivery and Neonatal Outcome in Nullipara of India, 2011-2014. Journal of clinical and diagnostic research. 2014; 8(10):OC03-6.

4. Liang CC, Wong SY, Chang YL, Tsay PK, Chang SD, Lo LM. Does Intrapartum Epidural Analgesia Affect Nulliparous Labor and Postpartum Urinary Incontinence? Chang Gung medical journal. 2007; 30(2):161-7.

5. Zimmer EZ, Jakobi P, Itskovitz-Eldor J, Weizman B, Solt I, A Glik A, et al. Adverse effects of epidural analgesia in labour. Eur J Obstet Gynecol Reprod Biol. 2000; 89:153-7.

6. Anim-Somuah M, Smyth RM, Cyna AM, Cuthbert A. Epidural versus non-epidural or no analgesia for pain management in labour. Cochrane Database Syst Rev. 2018 May 21; 5: CD000331.

7. Fairlie F, Phillips G, Andrews B, Calder A. An analysis of uterine activity in spontaneous labour using a microcomputer. British Journal of Obstetrics and Gynaecology. 1988; 95:57-6.

8. Antonakou A, Papoutsis D. The Effect of Epidural Analgesia on the Delivery Outcome of Induced Labour: A Retrospective Case Series. Obstet Gynecol Int. 2016; Epub 2016 Nov 20.

9. Leighton BL, Halpern SH. The effects of epidural analgesia on labor, maternal, and neonatal outcomes: a systematic review. Am J Obstet Gynecol. 2002 May; 186 (5 Suppl); S 69-77

10. Hamza J. Effect of epidural anaesthesia on the fetus and the neonate. Cah Anesthesiol. 1994; 42(2): 265-73.

11. Capogna G. Effect of epidural Analgesia on fetal heart rate. Eur J Obstet Gynecol Reprod Biol. 2001; 98(2): $160-4$

\footnotetext{
Amrita Chaurasia ${ }^{1}$, Nidhi Sachan ${ }^{2}$, Neelam Singh ${ }^{3}$

${ }^{1}$ Prof and Head, Dept of OBGY, MLNMC, Prayagraj, India; ${ }^{2}$ Assistant Prof, Dept of OBGY, MLNMC, Prayagraj, India; ${ }^{3}$ Prof, Dept of Anaesthesiology, MLNMC, Prayagraj, India.
} 